Too often the report shows little knowledge of how the family doctor deals with social as well as medical problems in the day-to-day care of his patients. Discussing the relationship between doctors and social workers it describes the latter as "acquiring insight and understanding" and "setting store by skills that could help patients better to understand their situation"; while medicine is said to be ever refining its objectivity and technology. Not many general practitioners see their role as technicians, nor would they be prepared to hand over the tasks of reassurance, comfort, and advice to social workers. Similarly, the committee's bland assumption that the traditions of professional confidence are increasingly anachronistic and that a new code should be devised will astonish many doctors. "Confidential information is exchanged freely" in many fields, says the report. It should not be.

Its approach to the future roles of doctors and social workers is regrettable, as in many parts of the country they are working together well. Fortunately the report gives high priority to the assignment of social workers to doctors' practices-particularly group practices and health centres. Whatever social scientists may believe, when in trouble patients turn first to their doctor ; and they look to him to sort things out. The report is apparently horrified that the doctor should be expected to lead the team coping with personal problems. Doctors believe that this is their responsibility, and ask only for the chance to have the staff to get on with the job. The public would almost certainly agree with them.

\section{Penetrating Wounds of the Abdomen}

The incidence of stab wounds of the trunk is increasing in Great Britain. $^{1}$ G. Roberts and E. Lavelle ${ }^{2}$ found that, whereas in 1957 and 1958 there were only one or two admissions a year from this cause to the Birmingham Accident Hospital, by 1962 the numbers had grown to one a month. They note that this increase is being seen in many other British cities apart from Birmingham and is particularly marked in city hospitals which serve a migrant or dockside population. A few of these injuries are due to accidents, particularly among certain occupations at risk, such as butchers, and a few result from attempts at suicide. But the great majority are sustained in fights by young adult males, usually after the public houses have closed in the evening. Roberts and Lavelle advise laparotomy in all cases of abdominal stab wounds, even if it is thought that the peritoneum has not been penetrated, since they stress that even a trivial pen-knife wound may penetrate an abdominal viscus.

This, one might say standard, textbook plea for exploration of every penetrating abdominal wound has recently been challenged. R. I. Ryzoff and his colleagues ${ }^{3}$ have published their experience of what they call "selective conservatism" in treating the results of penetrating abdominal injuries, and they review no fewer than 535 penetrating wounds treated at the King's County Medical Centre in Brooklyn. Of these, 477 were stab injuries, 50 gun shot wounds, and 8 miscellaneous. More than $20 \%$ of their patients were drunk at the time of initial examination. Operation was advised if there were clinical signs of peritoneal irritation, if the peritoneal aspirate showed blood or intestinal contents, if $x$-ray examination showed free intra-abdominal gas, or if the patient was in unexplained and persistent shock. On this regimen no fewer than $72 \%$ of patients admitted could be treated without laparotomy. There were only two deaths: one was from associated head injury, and the other was the result of haemorrhage into the chest and peritoneal cavity when these criteria were not exactly followed. Of 150 patients operated upon, 11 died $(7.3 \%)$. In this group 44 were found not to require any intra-abdominal treatment, 21 because bleeding had already stopped (for example, from a liver wound or retroperitoneal injury) and 23 because nothing was found at laparotomy. At Baragwanath Hospital, Johannesburg, there is a high admission rate for stab wounds among the non-white population which this hospital serves. Indeed, annually some 2,300 cases are dealt with. V. E. Sorour and P. J. Bijlsma ${ }^{4}$ have recently reported on 100 consecutive patients with stab wounds of the abdomen admitted to one of the surgical firms over a period of 18 months. Of these, 32 were managed conservatively because of the clinical absence of peritonitis. They required only two or three days' observation in hospital, and no complications developed among them.

At the Harlem Hospital, New York, however, A. de L. Maynard and G. Oropeza ${ }^{5}$ have recently strongly criticized the conservative surgical approach to the management of penetrating abdominal wounds. Over a ten-year period they dealt with 447 penetrating injuries, 371 being stab wounds and 76 gun-shot wounds. In many cases physical signs were confusing owing to associated severe trauma to the head or to the effects of heroin and alcohol ; alcoholics comprise $35 \%$ of the series. These authors report that they repeatedly found marked clinical signs of peritoneal irritation and yet at laparotomy nothing was found (63 patients). In contrast, 42 patients with negative findings before operation were shown at operation to have visceral injury. Only nine patients without clear-cut abdominal findings were treated conservatively, but all of these later developed physical signs of peritoneal irritation and all were subjected to laparotomy 12 hours to five days after injury. In three of these cases exploration was negative, but the remainder all had visceral injuries, four patients developing a stormy and prolonged postoperative course and a fifth dying of peritonitis. These authors advise that when there is doubt whether the peritoneum has been penetrated, it is reasonable to perform a small exploratory incision alongside the stab wound and carried down to the peritoneum via muscle retraction or muscle splitting. It is then possible to inspect the peritoneal surface in relation to the wound and to determine whether or not it has been breached.

We can be thankful in Britain that we have not been exposed to epidemics of violence, and indeed few of the surgical registrars today who deal with the bulk of abdominal emergencies will have had any extensive experience of penetrating abdominal wounds. Such cases in this country are relatively few, and there would seem little doubt that here the safe policy is to carry out a careful exploration in every case of penetrating wound of the abdominal wall.

Brit. med. F., 1967, 3, 813.

, Roberts, G., and Lavelle, E., Brit. F. Surg., 1966, 53, 88.

- Ryzoff, R. I., Shaftan, G. W., and Herbsman, H., Surgery, 1966, 59, 650 .

- Sorour, V. E., and Bijlsma, P. J., S. Afr. F. Surg., 1966, 4, 85.

- Maynard, A. de L., and Oropeza, G., Amer. F. Surg., 1968, 115, 307. 